\title{
Level of Computational Thinking Skills among Secondary Science Student: Variation across Gender and Mathematics Achievement
}

\author{
Samri Chongo ${ }^{1 *}$, Kamisah Osman ${ }^{1}$, Nazrul Anuar Nayan ${ }^{2}$ \\ ${ }^{1}$ Faculty of Education, National University of Malaysia, ${ }^{2}$ Faculty of Engineering and Built Environment, National University of Malaysia \\ *Corresponding Author: samrichongo@gmail.com
}

\section{ABSTRACT}

Computational thinking (CT) is often associated with computer science and mathematics in general. However, the involvement of computer science according to gender is seen to be imbalanced. Therefore, this study aimed to identify the level of students' CT skills by gender and their relationship to achievement in mathematics. The study employed survey research design and purposive sampling that involved 128 participants from four science stream students in one of the states in Malaysia $(n=128)$. The measurement of CT skills was done using a modified CT test adapted from the previous studies. The results of the study were analyzed using descriptive and inferential statistics. Spearman correlational analysis was applied to examine the relationship between CT skill and mathematical achievement and students' t-test analysis was used to determine the difference in CT skills across gender. The study found that the students' CT skills were at the honors level. The relationship between CT skills and mathematics achievement was statistically significant, whereas there exist no significant gender differences in CT skills. This study suggests that the teaching of mathematical logic needs to be considered to improve students' CT skills.

KEY WORDS: computational thinking; science students; gender differences; mathematics achievement; higher-order thinking skills

\section{INTRODUCTION}

I

$\mathrm{n}$ the $21^{\text {st }}$ century, we would argue that every country wants to create a society that can solve problems by thinking critically, creatively, and innovatively. As a result, many countries have focused on higher-order thinking skills (HOTS) in the education system to compete in the global digital economy. However, based on the results of the Program of International Student Assessment (PISA), Malaysian students exhibit a moderate level of problem-solving skills. As a result, in 2017, the integrated curriculum secondary school (KBSM) curriculum changed to the standard curriculum secondary school (KSSM), and computer science subjects were introduced at the secondary level to equip students with programming skills and an understanding of algorithms to produce creative, innovative, and dynamic students (KPM, 2016a).

Science stream students in Malaysia are those taking classes in physics, chemistry, and biology. These streams have an admission requirement dependent on science and mathematics achievements based on the Form Three Assessment (PT3) conducted by the Ministry of Education (KPM). Malaysia needs 493,830 scientists and engineers (Wan Nor Fadzilah et al., 2017); however, there were only 97,095 science stream students that sat for the Malaysian Certificate of Education (Sijil Pelajaran Malaysia; SPM) in 2017 (KPM, 2018) and 314,095 science students (science and technical) in 2016 (KPM, 2016b). In Malaysia, issues associated with science, technology, engineering, and mathematics (STEM) education include shortages of learning materials, a declining number of students pursuing STEM in secondary or higher education, and a deterioration in student achievement at home and in international benchmarking studies, such as the Trends in International Mathematics and Science Study and the PISA (Wan Nor Fadzilah et al., 2017). This issue was discussed by Kamisah and Rohaida (2014) who evaluated STEM issues based on teaching and learning ( $\mathrm{T}$ and $\mathrm{L}$ ) approaches that do not relate to real-life situation and the integration of STEM into science subjects. Therefore, the use of technology, such as computers, should be emphasized by teachers in the $\mathrm{T}$ and L process (Salihuddin et al., 2016).

The use of computer-based learning is a $\mathrm{T}$ and $\mathrm{L}$ method that can enhance HOTS (Salihuddin et al., 2016); however, thinking skills alone are inadequate. For example, computer use in chemistry $\mathrm{T}$ and $\mathrm{L}$ requires a problem-solving approach and a tool for solving problems through computational thinking (CT). One objective of computer science education includes the application of algorithms using logic to solve complex problems through CT (KPM, 2016a). The goals of computer science include motivating students to go beyond the screen and investigate how computers work and solutions for various problems (Sysło and Kwiatkowska, 2015). CT is a cognitive process involving logical thinking to solve problems and better understand procedures and systems (Csizmadia et al., 2015). 
Olabe et al. (2014) found that new pedagogical approaches, such as simple programming using Scratch, showed an ability to solve real-life problems. CT skills need to be integrated into pure science subjects to allow their application to solve problems more systematically and improve the number and abilities of science stream students.

Each student exhibits different levels of CT skills based on area, gender, and achievement in mathematics. CT skills are among the elements that teachers need to consider before integrating CT into any subject, especially those involving science students (e.g. chemistry, physics, and biology). CT skills need to be identified at an early stage to plan more effectively CT-based activities. Acquisition of CT skills will be important in future (Saritepeci, 2019), with CT ability often associated with mathematical logic and gender favoring males. Therefore, the purpose of this study was to identify CT levels, relationships between CT skills and mathematical achievement, and differences in CT skills by gender. The three research questions were: (1) What are students CT skill level, (2) is there a relationship between CT skills and mathematical achievement, and (3) are there differences in CT skills based on gender? The study developed two null hypotheses:

$\mathrm{H}_{1}$ : There is no significant relationship between CT skills and mathematical achievement.

$\mathrm{HO}_{2}$ : There is no significant difference in CT skills by gender.

\section{LITERATURE REVIEW}

CT skills involve problem-solving, system design, and understanding human behavior by illustrating basic concepts in computer science (Wing, 2006). In 2010, Wing introduced a new definition of CT describing it as a thinking process involved in formulating problems and representing solutions in a form that can be effectively implemented by an information-processing agent. According to Chao (2016), CT involves a visual problemsolving environment for allowing acquisition of programming skills with technological support of computational problemsolving. These definitions focus on the use of technology, specifically computer science, for solving problems. Although there is no consensus definition of CT (Román-González et al., 2018), it can generally be defined as a process of thinking and a tool for solving problems using computer concepts either with a computer (plugged-in) or without one (unplugged).

Computer science combines mathematical and engineering concepts and relies heavily on a mathematical foundation (Wing, 2006). CT is the ability to understand and apply the basic principles of computer science (KPM, 2016a) and allows operation of complex systems to address real-world problems (Wing, 2008). STEM students are particularly well suited for CT and its future applications (León et al., 2014). CT skills potential offer a higher level of problem-solving skills (Sridaran and Shailaja, 2015). Wing (2006) states that CT is not only applied by computer scientists but also by anyone with basic problem-solving skills.
The involvement of male and female students in STEM fields needs to be balanced to avoid gender discrimination (Sexton, 2017). In terms of CT skills, there is little difference between men and women. The previous studies report no difference in CT skills between male and female students aged 1518 years (Atmatzidou and Demetriadis, 2016; Korkmaz and Oluk, 2016); however, gender differences are inconsistent (Atmatzidou and Demetriadis, 2016). In most cases, female students require more time in their training sessions to achieve the same CT skills as males (Atmatzidou and Demetriadis, 2016), although such skills encourage students, especially women, to pursue STEM (Repenning et al., 2015) and especially computer science. In addition, differences in CT skills between men and women can be influenced by several factors, with Grover et al. (2015) showing that female students spend more time online after school demonstrating better CT skills than males; however, there remain few female students in STEM fields, especially at the university level (Shute et al., 2017).

\section{METHODOLGY}

\section{Research Design}

This study used a quantitative approach to perform a survey to evaluate CT skill level, its relationship to mathematics achievement (PT3), and differences in CT skills by gender. The survey design was used to obtain CT skill level information from 128 samples of form four science students studying at public secondary school.

\section{Population and Samples}

This study was conducted in a district of Tawau in the state of Malaysia, with the study population comprising science stream students in secondary schools ( $\sim 16$ years old) taking chemistry. The study cohort included 432 students comprising 137 boys and 295 girls and adhered to certain criteria with an aim to generalize the findings based on the characteristics of people or events in the population (Mcmillan, 1996). The study samples included 128 students used methods of purposive sampling, and sampling was applied to selected individuals based on their experience level (Creswell, 2009).

\section{Instrument}

The CT skills test was adapted from the UK Bebras Computational Challenge (Blokhuis et al., 2015; 2016; Blokhuis et al., 2017). There are five CT skills exhibited by students: Abstraction, algorithmic thinking, decomposition, evaluation, and generalization (Csizmadia et al., 2015; Selby and Woollard, 2013). There are 15 objective questions with difficulty levels according to a specified ratio and comprising four difficult questions $(26.7 \%)$, seven moderate questions (46.7\%), and four simple questions (26.7\%). Student mathematics achievement is based on PT3 results from the Ministry of Education in 2018 and includes five grades: Excellent (A), credit (B), good (C), satisfactory (D), and reached minimum level $(\mathrm{E})$. Student $\mathrm{CT}$ levels were determined based on scores from the modified CT test according to the 
SPM grades, which can be categorized into four levels based on the percentage of marks obtained: Excellence (70-100), credit (50-70), pass (40-49), and fail (0-39) (Table 1). The difficulty and percentage of questions concerning CT skills are shown in Table 2.

\section{Data Analysis}

In a $\mathrm{CT}$ test comprising 15 objective questions, an analytical scoring method was used, where each correct answer received a score that was then converted to a percentage. Student achievement in PT3 mathematics and gender was derived from the profiles of student taking the CT test. Data analyses involved descriptive statistics and inferential statistics, with descriptive statistics used to identify student CT levels, and inference statistics using Spearman's correlation applied to determine relationships between CT skills and mathematics achievement. A Student's $t$-test was used to determine significant differences in CT skills by gender.

\section{FINDINGS AND DISCUSSION}

The results were analyzed using descriptive statistics to evaluate levels of student CT skills in terms of frequency (f), percentage (\%), and mean and standard deviation, whereas inferential statistics was used to examine the relationship of CT skill level with mathematical achievement and gender differences according to correlation analysis and $t$-tests after normality testing.

\section{Normality Tests}

Normality tests were performed to determine the parametric or non-parametric nature of the data. Here, we used the Kolmogorov-Smirnov test and histograms to determine that the data were normally distributed and that differences in CT skills were not significant, $\rho>0.05(\mathrm{KS}=0.093, \mathrm{df}=128$, $\rho=0.08$ ). The data distribution of student CT skill levels is shown in Figure 1.

\section{Levels of Student CT Skills}

The level of CT-based knowledge and the percentage of CT skills among science stream students by category are shown in Table 3. Overall, respondent CT skill levels were moderate or credit based on CT skills level $(\mathrm{M}=52.42, \mathrm{SD}=16.995)$, with $<15 \%$ of respondents achieving excellent and $17.2 \%$ failing. The level of CT skills could be categorized into four stages: Fail, pass, credit, and excellence.

\section{Identifying a Relationship between CT Skills and Mathematic Achievement (PT3)}

The null hypothesis $\left(\mathrm{Ho}_{1}\right)$ states that there is no relationship between $\mathrm{CT}$ skills and mathematics achievement. Table 4 shows the level of student achievement in mathematics (PT3) from public examinations when students in form three. The data show that $46.9 \%$ of students achieved distinction ("A"), and only $0.8 \%$ achieved the minimum ("E").

Table 5 shows a significant correlation between CT skill and mathematics achievement, thereby rejecting the first null

\begin{tabular}{lclll}
\hline \multicolumn{4}{l}{ Table 1: CT skills level } \\
\hline SPM grades & Marks & Details & Marks & CT skills level \\
\hline $\mathrm{A}+$ & $90-100$ & Supreme excellence & $70-100$ & Excellence \\
$\mathrm{A}$ & $80-89$ & High excellence & & \\
$\mathrm{A}-$ & $70-79$ & Excellence & & \\
$\mathrm{B}+$ & $65-69$ & Supreme credit & $50-70$ & Credit \\
$\mathrm{B}$ & $60-64$ & High credit & & \\
$\mathrm{C}+$ & $55-59$ & Upper credit & & \\
$\mathrm{C}$ & $50-54$ & Credit & & \\
$\mathrm{D}$ & $45-49$ & Upper pass & $40-49$ & Pass \\
$\mathrm{E}$ & $40-44$ & Pass & & \\
$\mathrm{G}$ & $0-39$ & Fail & $0-39$ & Fail \\
\hline CT: Computational thinking & &
\end{tabular}

\begin{tabular}{|c|c|c|c|}
\hline Question & Element of CT skills & Difficulty level & Percentage (\%) \\
\hline 1 & Algorithmic thinking & Easy & 26.7 \\
\hline 2 & Abstraction & & \\
\hline 3 & Algorithmic thinking & & \\
\hline 4 & Decomposition & & \\
\hline 5 & Abstraction & Moderate & 46.7 \\
\hline 6 & Evaluation & & \\
\hline 7 & Generalization & & \\
\hline 8 & Decomposition & & \\
\hline 9 & Algorithmic thinking & & \\
\hline 10 & Abstraction & & \\
\hline 11 & Generalization & & \\
\hline 12 & Decomposition & Hard & 26.7 \\
\hline 13 & Evaluation & & \\
\hline 14 & Generalization & & \\
\hline 15 & Evaluation & & \\
\hline Total & & & 100 \\
\hline
\end{tabular}

\begin{tabular}{lcccc}
\hline \multicolumn{4}{l}{ Table 3: Level of students' CT skills } \\
\hline $\begin{array}{l}\text { CT skills } \\
\text { levels }\end{array}$ & Frequency & Percentage & $\begin{array}{c}\text { Valid } \\
\text { percentage }\end{array}$ & $\begin{array}{c}\text { Cumulative } \\
\text { percentage }\end{array}$ \\
\hline Fail & 22 & 17.2 & 17.2 & 17.2 \\
Pass & 37 & 28.9 & 28.9 & 46.1 \\
Credit & 50 & 39.1 & 39.1 & 85.2 \\
Excellence & 19 & 14.8 & 14.8 & 100.0 \\
Total & 128 & 100.0 & 100.0 & \\
\hline
\end{tabular}

hypothesis. Spearman's correlation suggested a moderate and significantly positive relationship between CT skill and mathematics achievement $(\mathrm{r}=0.322, \mathrm{n}=128 ; \rho<0.05)$.

These results show that achievement in mathematics can promote CT skills through the application of logical thinking. Randles and Overton (2015) explained that expert problem solvers develop a strategy and apply a logical and scientific approach to solving problems. Moreover, the previous studies report a close relationship between $\mathrm{CT}$ and mathematics ability (Weintrop et al., 2016). Wing (2006) indicated that 


\begin{tabular}{lccccc}
\hline \multicolumn{2}{l}{ Table 4: Students' achievement in mathematics (PT3) } & & & \\
\hline Mathematics achievement (PT3) & Grade & Frequency & Percentage & Valid percentage & Cumulative percentage \\
\hline Reached minimum level & $\mathrm{E}$ & 1 & 0.8 & 0.8 & 0.8 \\
Satisfying & $\mathrm{D}$ & 5 & 3.9 & 3.9 & 4.7 \\
Good & $\mathrm{C}$ & 23 & 18.0 & 30.5 & 22.7 \\
Credit & $\mathrm{B}$ & 39 & 30.5 & 46.9 & 53.1 \\
Distinction & $\mathrm{A}$ & 60 & 46.9 & 100.0 & 100.0 \\
Total & & 128 & 100.0 & & \\
\hline
\end{tabular}

\section{Table 5: Relationship between CT skills and mathematics} achievement (PT3)

\begin{tabular}{lllc}
\hline & & CT levels \\
\hline Spearman's rho & Mathematic & Correlation coefficient & $0.322^{* *}$ \\
& achievement & Sig. (two tailed) & 0.000 \\
& $\mathrm{n}$ & 128 \\
\hline **Correlation is significant at the 0.01 level (two tailed). CT: Computational \\
thinking
\end{tabular}

\begin{tabular}{|c|c|c|c|c|c|c|}
\hline Gender & $\begin{array}{c}\text { Number of } \\
\text { participants (N) }\end{array}$ & Mean $(\bar{x})$ & $\begin{array}{c}\text { Std. } \\
\text { deviation }\end{array}$ & $t$ & df & Sig. \\
\hline Male & 57 & 52.51 & 17.29 & 0.055 & 126 & 0.956 \\
\hline Female & 71 & 52.35 & 16.88 & & & \\
\hline
\end{tabular}

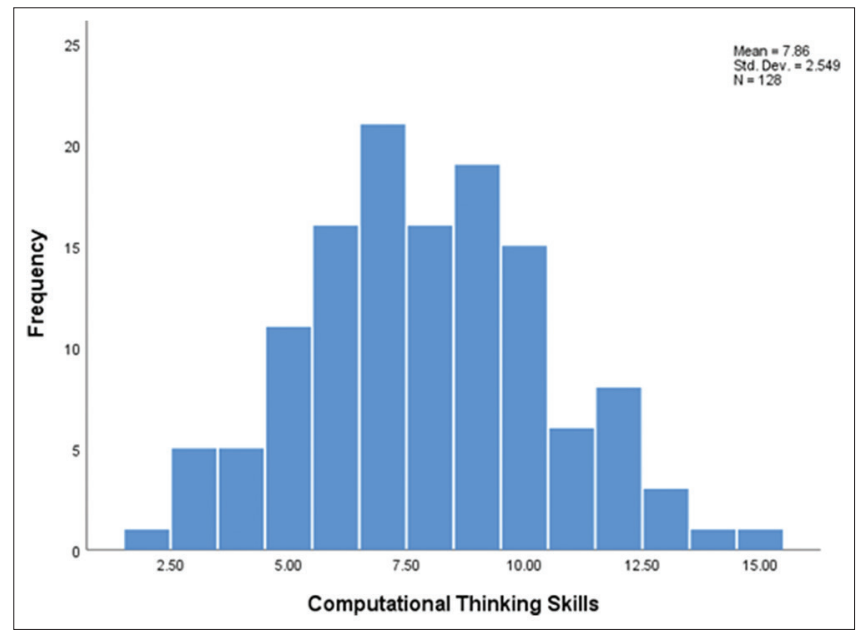

Figure 1: Normality test for computational thinking (CT) skills test

$\mathrm{CT}$ is not only relevant to science and mathematics but also for all subjects, including the humanities. Activities should be designed to be easily adopted and integrated into existing mathematics and science curricula (Weintrop et al., 2016). A study from New Zealand reported early integration of mathematics and language studies as effective for teachers (Bell And Sexton, 2018). Applications of CT skills for instruction of reading, writing, and arithmetic can enable children to think analytically while solving problems (Wing, 2006). To ensure students understand such concepts, CT-based activities should be relevant to real-world problems (Bell and Sexton, 2018).

\section{Identifying Gender-Based Differences in CT Skills}

Testing of the second null hypothesis $\left(\mathrm{Ho}_{2}\right)$ revealed no significant difference between males and females in terms of CT skills $(t=0.055 ; \mathrm{df}=126, \rho>.05)$. The $t$-test analysis results shown in Table 6 , and a relationship between gender $\mathrm{CT}$ skills was weak. These results suggest that gender does not play a significant role in student CT skills. This result agrees with Korkmaz and Oluk (2016) who previously reported no significant differences in CT skills according to gender. Conversely, Atmatzidou and Demetriadis (2016) showed that females require more time to obtain similar levels of CT skills as males. However, the present study indicated that integrating CT skills are not influenced by gender.

\section{CONCLUSION}

The level of CT proficiency and the elements that influence the outcomes needs to be identified before integrating it into a curriculum. Therefore, identifying levels of student CT skills are important for planning student activities to allow effective application of CT skills. These findings showed that gender factors do not influence CT skills, whereas mathematic achievement is related to CT skills. Therefore, basic mathematical knowledge, including computational areas involving algorithms, should be emphasized early in $\mathrm{T}$ and $\mathrm{L}$ activities to enhance critical thinking skills. Improvements in critical thinking skills will stimulate students to solve problems, thereby enhancing CT skills and student engagement in STEM fields.

\section{REFERENCES}

Atmatzidou, S., \& Demetriadis, S. (2016). Advancing students'computational thinking skills through educational robotics: A study on age and gender relevant differences. Robotics and Autonomous Systems, 75, 661-670.

Bell, S.E. \& Sexton, S.S. (2018). Science education professional development for primary/elementary teachers: A tale of two systems. Science Education International, 29(2), 117-123.

Blokhuis, D., Csizmadia, A., Millican, P., Roffey, C., Schijvers, E., \& Sentence, S. (2017). UK Bebras Computational Thinking Challenge. UK Bebras. Available from: http://www.bebras.uk/answer-booklets. $\mathrm{html}$.

Blokhuis, D., Millican, P., Roffey, C., Schrijvers, E., \& Sentance, S. (2015). UK Bebras Computational Thinking Challenge 2015. UK Bebras. Available from: http://www.bebras.uk/answer-booklets.html.

Blokhuis, D., Millican, P., Roffey, C., Schrijvers, E., \& Sentance, S. (2016). UK Bebras Computational Thinking Challenge. UK Bebras. Available from: http://www.bebras.uk/answer-booklets.html.

Chao, P.Y. (2016). Exploring students' computational practice, design and performance of problem-solving through a visual programming 
environment. Computers and Education, 95, 202-215.

Creswell, J.W. (2009). Research Design: Qualitative, Quantitative and Mixed Methods Approaches. $3^{\text {rd }}$ ed. New York, United States: Sage Publication, Inc.

Csizmadia, A., Curzon, P., Humphreys, S., Ng, T., Selby, C., \& Woollard, J. (2015). Computational Thinking: A Guide for Teachers. California, United States: Computing At School.

García, P., José, F., \& Mendes, A.J. (2017). Exploring the computational thinking effects in pre-university education. Computers in Human Behavior, 80, 407-411.

Grover, S., Pea, R., \& Cooper, S. (2015). Designing for deeper learning in a blended computer science course for middle school students. Computer Science Education, 25(2), 199-237.

Kamisah, O., \& Rohaida, M.S. (2014). Editorial: Science, technology, engineering and mathematics (STEM) education in Malaysia. EURASIA Journal of Mathematics Science and Technology Education, 10(3), 153154.

Korkmaz, Ö., \& Oluk, A. (2016). Comparing students' scratch skills with their computational thinking skills in terms of different variables how to teach computational thinking view project instructional technology view project comparing students' scratch skills with their computational. Modern Education and Computer Science, 11, 1-7.

KPM. (2016a). Basics Computer Science: Standard Curriculum and Assessment Document. Putrajaya: KPM.

KPM. (2016b). Malaysia Educational Statistics. Report No. Putrajaya: KPM. Available from: http://www.moe.gov.my.

KPM. (2018). Announcement of 2017 Malaysian Education Certificates (SPM) Result Analysis. Report No. Putrajaya. Available from: $\quad$ http://www.lp.moe.gov.my/images/bahan/spm/2018/ PengumumanAnalisisKeputusanSPM2017.pdf.

León, J., Núñez, J.L., \& Liew, J. (2014). Self-determination and STEM education: Effects of autonomy, motivation, and self-regulated learning on high school math achievement. Learning and Individual Differences, 43, 156-163.

Mcmillan, J.H. (1996). Educational Research: Fundamentals For The Consumer. $2^{\text {nd }}$ ed. New York, United States: Haper Collins Publisher Inc.

Olabe, J.C., Basogain, X., Olabe, M.Á., Maíz, I., \& Castaño, C. (2014). Solving math and science problems in the real world with a computational mind. New Approaches in Education Research, 3(2), 75-82.

Randles, C.A., \& Overton, T.L. (2015). Expert vs novice : Approaches used by chemists when solving open-ended problems. Chemistry Education Research and Practice, 16(4), 811-823.

Repenning, A., Webb, D.C., Koh, K., Nickerson, H., Miller, S.B., Brand, C., Horses, I., Basawapatna, A., Gluck, F., Grover, R., Gutierez, K.,
\& Repening, N. (2015). Scalable game design : A strategy to bring systemic computer science education to schools through game design and simulation creation. ACM Transactions on Computing Education, $15(2), 1-31$.

Román-González, M., Pérez-González, J.C., Moreno-León, J., \& Robles, G. (2018). Extending the nomological network of computational thinking with non-cognitive factors. Computers in Human Behavior, 80, 441-459.

Salihuddin, M.S., Hasnah, M., Zaleha, A., Norasykin, M.Z., Baharuddin, A., \& Mageswaran, S. (2016). Enhancing student's higher order thinking skills (HOTS) through the socratic method approach with technology. In: $1^{\text {St }}$ ICRIL-International Conference on Innovation in Science and Technology. Kuala: Universiti Teknologi Malaysia.

Saritepeci, M. (2019). Developing computational thinking skills of high school students: Design-based learning activities and programming tasks. The Asia Pacific Education Researcher, 29, 35-54.

Selby, C.C., \& Woollard, J. (2013). Computational Thinking: The Developing Definition. ACM. Available from: https://www.eprints. soton.ac.uk/356481.

Sexton, S. (2017). Meaningful intersections of social justice and contemporary cultural competencies in a New Zealand master's level initial teacher education programme. Journal of Contemporary Educational Research, 1(1), 33-42.

Shute, V.J., Sun, C., \& Clarke, J.A. (2017). Demystifying computational thinking. Educational Research Review, 22, 142-158.

Shailaja, J., \& Sridaran, R. (2014). Computational thinking, the Intellectual thinking for the $21^{\text {st }}$ Century. Available from: https://www.researchgate. net/publication/273776374_Computational_Thinking_The Intellectual_Thinking_for_the_21st_century.

Sysło, M.M., \& Kwiatkowska, A.B. (2015). Introducing a new computer science curriculum for all school levels in Poland. In: Brodnik, A., \& Vahrenhold, J., (Eds.), ISEEP 2015. LNCS 9378. Ljubljana: Springer. pp. 141-154

Wan Nor Fadzilah, W.H., Suhaiza, M.S., \& Lilia, H. (2017). The Inculcation of STEM Culture Outside the Classroom. Malaysia: UKM.

Weintrop, D., Beheshti, E., Horn, M., Orton, K., Jona, K., Trouille, L., \& Wilensky, U. (2016). Defining computational thinking for mathematics and science classrooms. Journal of Science Education and Technology, $25,127-147$

Wing, J.M. (2006). Computational Thinking. Communications of the ACM, 49(3), 33-35.

Wing, J.M. (2008). Computational thinking and thinking about computing. Philosophical Transactions of the Royal Society A, 366(1881), 37173725.

Wing, J.M. (2010). Computational Thinking: What and Why? Available from: https://www.cs.cmu.edu/ CompThink/resources/TheLinkWing.pdf. 